Real paths of Meteors observed in England, November 14-18 1903.

\begin{tabular}{|c|c|c|c|c|c|c|c|c|c|c|}
\hline No. & 1903 & Gr. M. T. & Mags. & $\begin{array}{c}\text { Height at } \\
\text { begina. }\end{array}$ & $\begin{array}{l}\text { Height } \\
\text { 2t end. }\end{array}$ & $\begin{array}{l}\text { Length } \\
\text { of path }\end{array}$ & $\begin{array}{l}\text { Velocity } \\
\text { per sec. }\end{array}$ & & $\begin{array}{l}\text { diant } \\
\text { oint }\end{array}$ & Observers \\
\hline & & & & miles & millos & miles & miles & $\alpha$ & 8 & \\
\hline I & Nov. I 4 & $10^{h} 4^{6 m}$ & $>I$ & 71 & 64 & 103 & $5^{1}$ & $149^{\circ}$ & $+24^{\circ}$ & AK, A. M. Davies \\
\hline 2 & -15 & 1018 & $>4>9$ & 79 & 42 & 48 & $3^{6}$ & 56 & +22 & T. W. Backhouse, A. Sullivan \\
\hline 3 & I 5 & 1318 & 2 & 73 & $5^{8}$ & 36 & 48 & 151 & +24 & CLB, WFD \\
\hline 4 & I 5 & 1342 & $>9$ & $7^{2}$ & $3^{2}$ & 47 & 23 & 61 & +24 & W. F. A. Ellison, John Mc. Harg \\
\hline 5 & 15 & 1359 & $2 \times q-3 \times q$ & 90 & 53 & 64 & - & 149 & +28 & W. F. A. Ellison, CLB, J. Mc. Harg \\
\hline 6 & $>15$ & $1559 \%$ & 4-I & 91 & 45 & 128 & 29 & 147 & $-\mathbf{I} \mathbf{I}$ & WFD, SJJ, W. Parkinson, F. H. Wright \\
\hline 7 & $>15$ & 1645 & $4-9$ & 77 & $5^{2}$ & 30 & 60 & 151 & +25 & ASH, WFD \\
\hline 8 & 15 & $1714^{1 / 2}$ & 4 & 77 & 52 & 30 & 45 & 152 & +25 & ASH, WFD \\
\hline 9 & 15 & 1723 & 4 & 84 & 63 & 27 & 67 & 149 & +19 & ASH, H. Corder \\
\hline 10 & 15 & 187 & $>x-2$ & 81 & 60 & 24 & 44 & I 5 I & +23 & ASH, AK, WFD \\
\hline II & 18 & 1244 & $9-1 / 3^{\text {th }} D$ & 75 & 33 & 51 & 33 & 50 & +20 & ASH, CLB \\
\hline
\end{tabular}

Nos. $1,3,5,7,8,9$ and 10 were Leonids and nearly all of them brilliant members of this rich stream. Nos. 2, 4 and 1 I were Taurid fireballs.

Observers: ASH, Prof. A. S. Herschel, Slough; AK, Alphonso King, Sheffield; CLB, C. L. Brook, Meltham, Huddersfield; SJJ, Rev. S. J. Johnson, Bridport; WFD; W. F. Denning, Bristol.

Bishopston, Bristol, 1904 Febr. 5.

W. IV. Denning.

\title{
Beobachtungen über den Zusammenhang zwischen Farbe und Helligkeit der Fixsterne; Von $H$. Osthoff.
}

Zur Feststellung des Verhältnisses zwischen Helligkeit und Farbe der Fixsterne habe ich eine Anzahl von Sternen meines Katalogs (A. N. 3657-58) von jeder Färbung und Größe ausgewählt und ihre Farben mit Blenden vor dem Objektiv beobachtet.

Ich wandte Blenden in der Form von Sektoren an, deren Mittelpunkt mit der Mitte des Objektivs zusammenfällt und zwar (da das Verhältnis $\frac{\text { volle Öffnung }}{\text { Offnungswinkel des Sektors }}$ gilt) zur Verminderung der Lichtstärke der Sterne um eine Größen. klasse eine Bedeckung von $216^{\circ}$ (durch drei Kreisausschnitte zu je $72^{\circ}$, und zur Verminderung um zwei Größenklassen eine Bedeckung von $3 \circ 3^{\circ}$ (durch drei Kreisausschnitte zu je $\operatorname{ror}^{\circ}$ ), so daß im ersten Falle $144^{\circ}$, im zweiten $57^{\circ}$ freie Offnung blieben.

Beobachtungsmethode, Instrument und Farbenskala blieben unverändert die nänlichen, wie ich sie von jeher angewandt hatte.

Aber während sich die Sternfarben bei Abblendung um I $^{\text {m }}$ noch bequem bestimmen ließen, war das nicht immer der Fall bei Anwendung der geringen Óffnung von $57^{\circ}$. Vielfach erschienen die Sterne dann als verzerrte, verwaschene Lichtflecken, grau, durchkreuzt oder umgeben von intensiven blauen oder roten Beugungsfarben.

Nur wenn das ganze Bild des Sternes gleichmäßig gefärbt erschien oder wenn eine vorwiegende Kernfarbe zu erkennen war, die sich in der Skala ausdrlicken ließ, wurde die gesehene Farbe notiert. Sterne 5. Größe vertrugen die Blenden uberhaupt nicht gut, falls sie nicht intensiv gefärbt waren und auch bei den Sternen der 4. Größe ließ sich die stärkere Abblendung nur auf die höheren Farbenstufen anwenden.
Ich habe Sorge getragen, die Blenden nur bei günstig. stem Luftzustande und in Abwesenheit des Mondlichtes anzuwenden. Das hatte die günstige Folge, daß oft Wochen und selbst Monate zwischen den einzelnen Beobachtungsabenden lagen, wodurch jede Erinnerung ausgetilgt wurde. Ferner habe ich die Vorsicht gebraucht, an einem Abend nur die erste, am andern nur die zweite Blende in Gebrauch zu nehmen oder einmal in der Reihenfolge $i$ und 2 , demnächst aber umgekehrt zu beobachten. Zwischendurch wurden gelegentlich die benutzten Sterne mit voller Öfnung beobachtet, ohne daß sich jedoch eine Änderung der Farben des Katalogs ergeben hătte.

Auf Gewinnung einer Beobachtungsreihe mit einer Abblendung um drei Größenklassen mußte ich verzichten, weil sich hier die Schwierigkeiten noch mehr häufen. Sichere Farbenschätzungen ließen sich nur bei den hellsten Sternen ermöglichen.

Den nachstehenden Vergleichungèn mit den Farben der Sterne meines Katalogs liegen im ganzen 1028 Schz̆tzungen mit Blenden an 86 Sternen zugrunde.

Anzahl der Sterne.

\begin{tabular}{c|c|c|c|c|c|c}
\hline & $\mathrm{I}^{\mathrm{m}}$ & $2^{\mathrm{m}}$ & $3^{\mathrm{m}}$ & $4^{\mathrm{m}}$ & $5^{\mathrm{m}}$ & \\
\hline $1^{0}$ & 2 & 4 & - & - & - & 6 \\
2 & - & 5 & 5 & 4 & - & 14 \\
3 & 3 & 1 & 6 & 3 & 1 & 14 \\
4 & 1 & 2 & 3 & 4 & 1 & $1 \mathrm{I}$ \\
5 & $\mathrm{I}$ & 3 & 4 & 4 & 2 & 14 \\
6 & 1 & 4 & 6 & 5 & - & 16 \\
7 & - & - & - & 3 & 8 & $1 \mathrm{I}$ \\
\hline & 8 & 19 & 24 & 23 & $\mathrm{I} 2$ & 86
\end{tabular}

